\title{
COVID-19 vaccination: An attempt to control the pandemic
}

\author{
Sabiha Armin BS, Anisa Wakil BS, James Tarbox MD, Kenneth Iwuji MD
}

\begin{abstract}
Background: Since the Severe Acute Respiratory Syndrome Coronavirus-2 was discovered in December 2019, there have been tireless efforts by the medical and scientific community to understand its pathophysiology, treatment, and prevention.

Discussion: In the last several months, several therapeutic treatments, including a corticosteroid, antiviral drugs, convalescent plasma, and several others, have been tried in the treatment of SARS-CoV-2 with varying results. Pfizer and Moderna COVID-19 vaccines recently received approval for Emergency Use Authorization. Although COVID-19 vaccine is the first hurdle in an attempt to control the pandemic, the following challenges still remain: adequate vaccine doses, issues with mass distribution, global access, proper storage, and sufficient vaccine compliance.

Summary: Vaccination, in addition to social distancing and wearing facemasks, will likely provide the best way to control the COVID pandemic. Healthcare professionals and government officials will need to address any concern or hesitancy the community has with the COVID vaccine to promote compliance.
\end{abstract}

Keywords: coronavirus therapeutics, herd immunity, coronavirus vaccine, vaccine targets, clinical trials

\section{INTRODUCTION}

Severe Acute Respiratory Syndrome Coronavirus2 (SARS-CoV-2, also known as COVID-19) is an enveloped, positive-stranded RNA virus containing spike-like projections of glycoproteins on its surface. ${ }^{1}$ The coronavirus genome encodes structural proteins, which are responsible for host infection through membrane fusion, viral assembly, and release of viral particles. ${ }^{2,3}$ Other proteins encoded in the genome facilitate viral replication and transcription. The membrane, the envelope, and the spike (S) protein make up the glycoproteins on the viral surface; the trimeric $S$ proteins protrude from the viral envelope and are

Corresponding author: Kenneth Iwuj

Contact Information: Kenneth.Iwuji@ttuhsc.edu

DOI: 10.12746/swrccc.v9i37.801 integral to viral entry into the host cell. ${ }^{1,3}$ The $S$ proteins, common among the coronaviruses, are a major target for eliciting antibodies; therefore, molecular details of the $S$ protein and its receptor interactions became the focus of vaccines and antiviral drugs against SARS-CoV-2.

Person-to-person transmission is primarily by aerosol particles during close encounters. The time from exposure to onset of symptoms is approximately 5 to 7 days; symptoms of the illness include fevers, cough, shortness of breath, nasal congestion, loss of taste or smell, muscle aches, vomiting, and diarrhea. ${ }^{4,5}$ Various approaches for prevention of transmission of this respiratory pathogen have focused on isolation of infected individuals or quarantine of those with high risk exposures at home, social distancing, hand hygiene, face masks, and temporary closure of schools and workplaces. Social isolation and face masks proved helpful in reducing the number of daily infections. 
Remdesivir, an antiviral agent that prevents the transcription of the viral genome by interfering with RNAdependent RNA polymerase, is the first FDA approved treatment for COVID-19, based on a trial conducted by Gilead Sciences. ${ }^{6}$ However, the therapeutic effectiveness of this drug has been questioned recently. On November 20,2020, the World Health Organization and other medical societies recommended against using remdesivir regardless of disease severity, due to insufficient data to support its clinical effectiveness on mortality, the need for mechanical ventilation, time to clinical improvement, and other patient outcomes. ${ }^{7,8}$ Similarly, passive immunity with hyperimmune plasma from recovered patients was recommended previously, but there is no strong evidence to support its continued use. .,10 $^{9}$

On November 9, 2020, the monoclonal antibody bamlanivimab (an investigational monoclonal antibody against the coronavirus -2 spike protein) received an Emergency Use Authorization. It has been used in the outpatient setting but is not currently approved for use in patients hospitalized for COVID-19 or patients requiring supplemental oxygen due to the lack of demonstrated efficacy in these patients. ${ }^{11,12}$ Glucocorticoids are used in current treatment plans based on the results of the RECOVERY trial showed that with intravenous dexamethasone (at a dose of $6 \mathrm{mg}$ once daily) for up to 10 days, there was a reduction in inflammation-mediated pulmonary fibrosis and subsequent progression to respiratory failure and death in patients who required mechanical ventilation. ${ }^{13}$

The FDA authorized Eli Lilly \& Co.'s baricitinib against the SARS-CoV-2 S glycoprotein on November 9,2020 , as researchers reported that drug lowered the risk of subsequent medical visits and reduced levels of virus in people with mild to moderate symptoms of COVID-19. ${ }^{14}$ On November 22, 2020, the FDA gave an Emergency Use Authorization to Regeneron's antibody treatment, which made headlines as it was given to President Donald Trump to treat COVID -19, with the concurrent IV administration of the casirivimab and imdevimab antibodies. ${ }^{15}$ Similar to the vaccine candidates, these antibodies block the receptor binding domain of SARS-CoV-2 S glycoprotein. Clinical trials showed a reduction in viral load and in the number of hospitalizations of high risk patients not requiring ventilatory support within 28 days after treatment when compared to placebo. Hospitalizations and emergency room visits occurred in 3\% of dual antibody-treated patients compared to $9 \%$ in placebo-treated patients. ${ }^{14,15}$ Although this is promising, casirivimab and imdevimab are associated with worse clinical outcomes when administered to critically ill patients who require high flow oxygen or mechanical ventilation. ${ }^{14}$ Currently, casirivimab and imdevimab treatment is being evaluated in an ongoing clinical trial as part of the Accelerating COVID-19 Therapeutic Interventions and Vaccines (ACTIV) public-private partnership led by the National Institutes of Health. ${ }^{16}$

\section{HERD IMMUNITY: WHY IT MAY NOT BE EFFECTIVE FOR COVID-19}

Herd immunity through natural infection for the SARS-CoV-2 in absence of a vaccine is not a feasible or ethical strategy. The herd immunity threshold is the percent of individuals in the population that must be immune to stop transmission of the virus. A more infectious agent will have a higher herd immunity threshold. ${ }^{17}$ Herd immunity threshold for COVID is approximately $82.5 \%$, which means the incidence of infections will not begin to decrease until the threshold of $82.5 \%$ is reached. However, several studies have shown that herd immunity thresholds must not be taken as constant. ${ }^{18}$ They can easily change based on human behavior and population dynamics. Nationwide commercial seroprevalence studies by the CDC show seroprevalence rates between $0.4 \%-22.5 \%$, demonstrating that achieving herd immunity without a vaccine would take an enormous toll on human lives and easily overwhelm healthcare facilities..$^{19,20}$

There is also a question about how long immunity to COVID lasts after natural infection. Wajnberg et al. analyzed blood samples from 30,000 people who had been infected with SARS-CoV-2 and found that more than $90 \%$ of those infected had moderate or high levels of antibodies in their blood, with a modest decline in antibody levels after 5 months. Experiments showed that these antibodies could block the virus from infecting cells. ${ }^{21}$ If the virus mutates frequently then herd immunity may never be reached. ${ }^{19}$ Therefore, 
pandemic strategies cannot use natural infection to achieve herd immunity, as this will lead to uncontrolled transmission. ${ }^{20}$

\section{DISCUSSION OF THERAPEUTICS AND TREATMENTS}

Studies of SARS-CoV-2 genomic sequences indicate that the receptor binding domain of the $S$ glycoprotein is highly conserved, providing hope for a successful vaccine directed at a stable target. Most vaccine trials are targeting the $S$ protein, which contains 2 subunits-S1 and S2, with a receptor binding site found on S1 (Figure 1). This S glycoprotein allows the virus to bind to the angiotensin converting enzyme 2 receptor complexes and heparan sulfate in the human cell membrane, causing a conformational change and eventual viral entry as a first step for infection. ${ }^{22}$

Table 1 summarizes information on four prominent vaccine developments that are in Phase III clinical trials. Moderna and Pfizer are mRNA vaccines that target the SARS-CoV-2 spike protein; each requires a booster vaccine 3 to 4 weeks after the initial vaccine. They were recently approved by the Food and Drug Administration for Emergency Use Authorization. mRNA vaccines use part of the viral genome instead of an inactivated virus and should have no risk of infection or incorporation into the host genome. ${ }^{23}$ mRNA vaccines are generally more stable and highly translatable, carry high potency, and have low manufacturing costs. ${ }^{24,25}$ Upon vaccination, host cells, such as dendrites, macrophages, and B cells, take up the

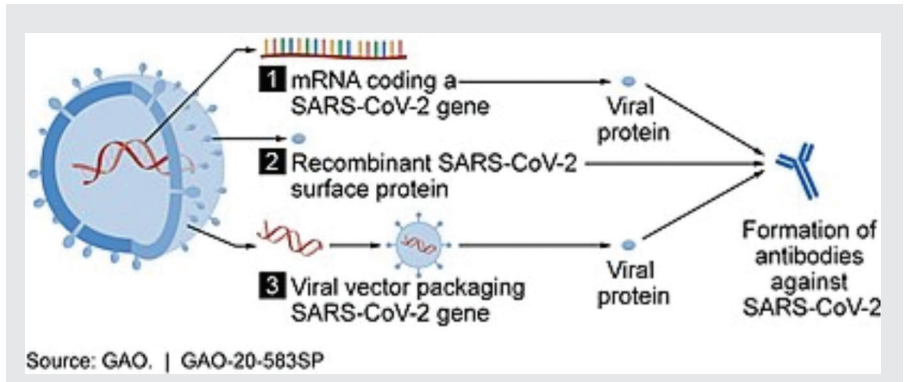

Figure 1. Coronavirus vaccine pathways. https:// en.wikipedia.org/wiki/COVID-19_vaccine.
mRNA, generate the protein, and then display those molecules to $T$ cells of the immune system. The host can then generate a cell-mediated immune response and form antibodies against the $S$ protein of the virus, preventing its entry into human cells. When the host is exposed to SARS-CoV-2, it will recognize the $S$ protein and destroy it before the virus invades cells for its replication, or it greatly decrease the number of cells that become infected.

Janssen and AstraZeneca used viral vectors for their vaccine development. Vector vaccines can be a replicating or non-replicating viral vector, attenuated or inactivated. Vector vaccines may allow a large genome insertion and therefore can target any antigen of choice. ${ }^{24}$ They could require multiple immunizations that lead to the host response against the structural viral proteins, limiting the efficacy of vaccination. Risks of integration into the host genome do potentially exist, as some viral vectors enter the nucleus of cells to achieve transcription and replication. A major restraint in the production of viral vector vaccines is the time consuming manufacturing. ${ }^{23}$ On September 11, 2020, AstraZeneca temporarily halted testing globally after a case of transverse myelitis was reported. Transverse myelitis is a segmental inflammation of the spinal cord that causes acute motor weakness, urinary retention, loss of sensation below a certain dermatome, and flaccid paralysis. The British company published a report saying "there was insufficient evidence to say for certain that the illnesses were or were not related to the vaccine."26 Similarly, Johnson \& Johnson paused its phase 3 ENSEMBLE trial after a volunteer experienced an unexplained illness after receiving the vaccine. The company did not disclose what the illness was due to privacy agreements with the participant, and it remains unclear whether the sick participant was in the treatment group or in the placebo group. ${ }^{27}$

DNA vaccines are also an option, although there are not currently any major companies marketing a DNA vaccine to combat COVID-19. Some DNA vaccine against COVID-19 are still in pre-clinical and phase 1 clinical trials. Historical examples of DNA vaccines include those for smallpox and Zika virus. DNA vaccines integrate into the viral genome, 
Table 1. Current Vaccine Development

\begin{tabular}{|c|c|c|c|c|}
\hline Company & $\begin{array}{l}\text { Vaccine Target } \\
\text { (Type of Vaccine) }\end{array}$ & Pros of Vaccine & Cons of Vaccine & $\begin{array}{l}\text { Enrollment } \\
\text { (Estimated } \\
\text { Completion Date) }\end{array}$ \\
\hline $\begin{array}{l}\text { Pfizer/ } \\
\text { BioNTech } \\
\text { BNT162b2 }\end{array}$ & $\begin{array}{l}\text { SARS-CoV-2 } \\
\text { spike (S) } \\
\text { glycoprotein } \\
\text { (mRNA) }\end{array}$ & $\begin{array}{l}\text { Efficacy of more than } 95 \% \\
\text { Systemic side effects events } \\
\text { (fatigue, headache, chills, } \\
\text { muscle pain and joint pain) } \\
\text { reported in small numbers }\end{array}$ & $\begin{array}{l}\text { Administered in two } 30 \mu \mathrm{g} \\
\text { dose } \\
\text { Requires dilution } \\
\text { Storage at }-70 \mathrm{C} \text { required } \\
\$ 20 \text { per dose }\end{array}$ & $\begin{array}{l}42,000 \\
\text { (June 13, 2021) }\end{array}$ \\
\hline $\begin{array}{l}\text { AstraZeneca } \\
\text { AZD1222 }\end{array}$ & $\begin{array}{l}\text { SARS-CoV-2 } \\
\text { spike (S) } \\
\text { glycoprotein } \\
\text { (Attenuated } \\
\text { Adenovirus- } \\
\text { chimpanzee } \\
\text { vector) }\end{array}$ & $\begin{array}{l}\text { Efficacy of } 90 \% \text { with half } \\
\text { dose shot, followed by full } \\
\text { dose booster } \\
\text { Systemic events (fatigue, } \\
\text { headache, chills, muscle pain } \\
\text { and joint pain) reported in } \\
\text { small numbers } \\
\text { Stored between 2-8 C } \\
\text { Expects to make 3 billion } \\
\text { doses next year } \\
\text { Priced on a nonprofit basis at } \\
\$ 3-\$ 5 \text { per dose } \\
\end{array}$ & $\begin{array}{l}\text { Efficacy of } 62 \% \text { with two } \\
\text { full doses both at the initial } \\
\text { and booster phase } \\
\text { Two reported cases of } \\
\text { transverse myelitis }\end{array}$ & $\begin{array}{l}40,051 \\
\text { (December 22, 2020) }\end{array}$ \\
\hline $\begin{array}{l}\text { Moderna } \\
\text { mRNA-1273 }\end{array}$ & $\begin{array}{l}\text { SARS-CoV-2 } \\
\text { spike (S) } \\
\text { glycoprotein } \\
\text { (mRNA) }\end{array}$ & $\begin{array}{l}\text { Efficacy of } 94.5 \% \\
\text { Does not require dilution } \\
\text { Stored at }-20 \mathrm{C} \text { or } \\
\text { refrigerator temperature for } \\
\text { up to } 30 \text { day }\end{array}$ & $\begin{array}{l}\text { Two } 100 \mu \text { g dose } \\
\text { intramuscular injections that } \\
\text { must be given weeks apart } \\
\text { Injection site pain; Post } \\
\text { second dose reported } \\
\text { fatigue, myalgia, arthralgia, } \\
\text { headache, pain and } \\
\text { erythema/redness at the } \\
\text { injection site } \\
\text { Priced at } \$ 35 \text { per dose }\end{array}$ & $\begin{array}{l}30000 \\
\text { (October 27, 2022) }\end{array}$ \\
\hline $\begin{array}{l}\text { Johnson and } \\
\text { Johnson/ } \\
\text { Janssen Ad26. } \\
\text { COV2.S }\end{array}$ & $\begin{array}{l}\text { SARS-CoV-2 } \\
\text { spike (S) } \\
\text { glycoprotein } \\
\text { (Non-replicating } \\
\text { Adenovirus-vector) }\end{array}$ & & $\begin{array}{l}\text { Phase } 3 \text { trial halted due to } \\
\text { "unexpected illness" in at } \\
\text { least two participants }\end{array}$ & $\begin{array}{l}90000 \\
\text { (September 15, 2021) }\end{array}$ \\
\hline
\end{tabular}

are generally more stable with easier delivery, but have lower potency when compared to other vaccine options. ${ }^{24}$ Like mRNA viruses, the DNA viruses elicit both type I and type II MHC responses that allows the CD4 and CD8+ T cells to induce an antibody response. The DNA must pass through both the cytoplasm and nuclear membranes to get to the target; RNA vaccines stimulate an immune response without entering the nucleus. DNA viruses are cheaper and easier to purify, with no issues of misfolding/incorrect induction of T cells compound to recombinant protein vaccines. 
There are no protein subunit vaccines currently on the market for COVID-19. Historical examples include pertussis, Haemophilus influenzae type B, and human papilloma virus vaccines. Protein subunit vaccines are known to be the safest form of vaccines because they do not contain pathogen-derived genetic information, and manufacturing does not require manipulation of live pathogens. They might represent a platform of choice when a fast response to an epidemic is needed, as the vaccine production can start once the genome of the new virus has been sequenced, even before viral isolation. ${ }^{23}$

\section{RECENT COVID-19 VACCINE BREAKTHROUGHS}

Moderna's vaccine trials had 30,000 participants, including more than 7,000 Americans who are at least 65 years old, and 5,000 Americans who are under age 65 but have chronic diseases, such as diabetes, severe obesity, and cardiac disease..$^{28}$ On November 16, 2020, Moderna reported that its intramuscular formulation of the mRNA-1273 vaccine met statistical criteria with a vaccine efficacy of $94.5 \%$. The preliminary data from the company's recently approved vaccine showed that 94 participants in the placebo group contracted COVID-19 versus 5 participants in the treatment group. In contrast to Pfizer and BioNTech's vaccine candidate, Moderna's vaccine consists of two $100 \mu \mathrm{g}$ dose intramuscular injections that must be given 4 weeks apart to achieve full efficacy since one dose does work but does not create as robust response and likely has shorter efficacy. It does not require dilution. In addition, the Moderna vaccine has fewer stringent shipping and handling constraints, similar to the influenza vaccine in ease of distribution, and can be stored at a refrigerator temperature for up to 30 days. Adverse events after vaccine administration were mostly mild or moderate. Two percent of Moderna's participants had severe events, including injection site pain, fatigue, myalgia, arthralgia, headache, pain, and erythema at the injection site..$^{28}$

The Pfizer and BioNTech vaccine trials have over 43,000 participants with $42 \%$ having diverse backgrounds. ${ }^{25}$ Their result showed over $95 \%$ effectiveness in the final analysis, consistent across all demographics. Efficacy in participants over 65 was $94 \%$. It is also administered on a two-dose schedule with two $30 \mu \mathrm{g}$ doses given 3 weeks apart. Severe adverse effects greater than or equal to $2 \%$ were fatigue and headache, with no given value on how many participants experienced those specific effects. ${ }^{25}$ Both Pfizer and Moderna vaccines recently were approved for emergency use authorization. Rare cases of anaphylactic reactions have been reported for both vaccines.

\section{FEARED COMPLICATIONS OF COVID-19 VACCINATION}

Since the onset of the COVID-19 pandemic, there have been reports of the possible link between Guillain-Barré syndrome (GBS) and the COVID-19 infection. ${ }^{29}$ This has created a concern that the same neurological diseases could be linked to COVID-19 vaccination as well. In most cases, the onset of the neurological symptoms related to GBS was about 1 to 4 weeks after the diagnosis of COVID-19. ${ }^{29}$ More than $70 \%$ of patients showed a good prognosis, mostly after treatment with intravenous immunoglobulin. Patients with less favorable outcomes were associated with a significantly older age in accordance with previous studies on both classic GBS and COVID-19. ${ }^{29}$ Transverse myelitis is another immune-mediated polyneuropathy that has been seen in rare cases after influenza vaccination..$^{30}$ It is similar to GBS in that it is an inflammatory response that affects nerves; however, this condition is characterized by the infiltration of the inflammatory cells into segments of the spinal cord leading to neuron death and demyelination. These symptoms can be managed with high-dose intravenous glucocorticoids and with plasmapheresis.

Fears regarding accelerated development of the vaccine are rampant in current news. FDA approval through the Emergency Use Authorization was done quickly, so, understandably, individuals who get vaccinated against other diseases may be hesitant to get COVID vaccinations due to safety concerns regarding the nature of the "new vaccine technology" and rapid development. With the vaccine given on a voluntary basis in the US, it is possible that concerns about side effects or efficacy could reduce vaccine compliance. mRNA vaccination technology is not entirely new as 
it has been studied and used in cancer research Pharmaceutical companies have been studying and developing mRNA vaccines to specifically target proteins on tumor cells, allowing human immune cells to recognize and then destroy malignant cells. ${ }^{31,32}$ In the case of targeted cancer therapy, it is not widely available because the immunotherapy must be custom made for each tumor due to the various mutations cancer cells employ to evade the immune system. The principle of this therapy has already been used to develop vaccines against other coronaviruses, such as MERS and SARS, but these vaccines were not manufactured on a global scale because the diseases never reached pandemic proportions. ${ }^{33}$

Nearly all RNA virus replication strategies are independent from the host cell nucleus and generate genomic copies through a viral RNA-dependent RNA polymerase in the cytoplasm. ${ }^{34}$ Consequently, few RNA viruses modify host gene expression and cause oncogenesis as most RNA virus replication strategies are segregated from the host genome. Some people think that the vaccine may cause excess proteins being formed by the mRNA component; however, this is not based in fact because human translation machinery has high fidelity with editing done by tRNA synthetase so errors in protein formation are expected to be minimal. ${ }^{35}$ Side effects are common after vaccine administration and are well documented as an inflammatory response to the vaccine components rather than to the microbe inoculate; the vaccine is not directly "giving hosts" the viral infection.

Mutations are not an uncommon complication in RNA based infections. This is seen in genetic drift and reassortment events, such as the one that created the $\mathrm{H} 1 \mathrm{~N} 1$ strain of influenza during the last pandemic. It is possible that a genetic drift or mutation could occur with the SARS-CoV-2 spike glycoprotein, causing the current vaccine candidates to become obsolete. Research must be done on the mutation rate of SARS-CoV-2 to assess if this will be an issue that must be addressed in the future.

Vaccine hesitancy is common among the minority population, primarily African Americans. This is rooted historically in the unethical Tuskegee's Syphilis Experiment conducted for 40 years by the United
States Public Health Service and Centers for Disease Control and Prevention. This experiment studied the long term natural history of untreated syphilis, and the African American participants in the study were lied to and made to believe that they were receiving free health care and syphilis treatment from the federal government of the United States. The aftermath of Tuskegee's experiment led Congress to pass the National Research Act of 1974. This law led to the establishment of the Office of Human Research Protection and Institutional Review Board (IRB) in any organization participating in human research.

Some Americans are also increasingly wary to accept the coronavirus vaccine despite drug companies releasing their protocols and study conclusions in an effort to be more transparent. Anecdotal evidence and the politicization of the vaccine have revealed many concerns in accepting a vaccine produced so quickly.

There are possible global inequities in distributing vaccines. The COVID-19 Vaccines Global Access (COVAX) plan was designed to allow fair access to the future vaccine, so that more developed countries that are able to afford buying the vaccine first and in bulk amounts would not be at an advantage for obtaining this treatment. ${ }^{36}$ The COVAX plan explains that countries in Latin America, Africa, and Asia will receive enough doses to vaccinate at least $20 \%$ of their population, starting with the most vulnerable and at-risk groups first.

\section{Conclusion}

There are many challenges to widespread COVID vaccinations, such as the production delays, need for subsequent booster shots, and vaccine storage. Vaccine candidates currently on the market require at least one booster shot several weeks after the first vaccine dose, which could create a challenge for treatment compliance due to missed follow-up. In addition, distributing the vaccine to rural areas presents well-known challenges, such as maintaining the cold chain with proper transportation (refrigeration or freezing) and adequate storage, facilities for administration, and staff to deliver the vaccine. 
While the development of a COVID-19 vaccine is the first hurdle in an attempt to control the pandemic, there are other important challenges left. After adequate vaccine doses are secured, issues with mass distribution prominent in other well-known vaccine programs must be addressed. There must be global access, proper storage, and sufficient vaccine compliance. Only then can herd immunity be achieved and hopefully stop the COVID-19 pandemic.

Article citation: Armin S, Wakil A, Tarbox J, Iwuji K. COVID-19 vaccination: An attempt to control the pandemic. The Southwest Respiratory and Critical Care Chronicles 2021;9(37):32-39

From: Department of Internal Medicine, Texas Tech University Health Sciences Center, Lubbock, Texas

Submitted: $12 / 22 / 2020$

Accepted: $1 / 5 / 2021$

Reviewer: Jacob Nichols MD

Conflicts of interest: none

This work is licensed under a Creative Commons

Attribution-ShareAlike 4.0 International License.

\section{REFERENCES}

1. Lan J, Ge J, Yu J, et al. Structure of the SARS-CoV-2 spike receptor-binding domain bound to the ACE2 receptor. Nature 2020;581:215-220. 10.1038/s41586-020-2180-5

2. Vennema H, Godeke GJ, Rossen JW, et al. Nucleocapsidindependent assembly of coronavirus-like particles by coexpression of viral envelope protein genes. EMBO J 1996;15: 2020-2028. 10.1002/j.1460-2075. 1996.tb00553.

3. Siu YL, Teoh KT, Lo J, et al. The M, E, and N structural proteins of the severe acute respiratory syndrome coronavirus are required for efficient assembly, trafficking, and release of virus-like particles. J Virol 2008;82:11318-11330. 10.1128/ JVI.01052-08

4. Saa L, Iwuji K. Coronavirus Disease 2019: A threat to global health. The Southwest Respiratory and Critical Care Chronicles 2020;8(34),4-10. https://doi.org/10.12746/swrccc. v8i34.673

5. Wiersinga WJ, Rhodes A, Cheng AC, et al. Pathophysiology, transmission, diagnosis, and treatment of coronavirus disease 2019 (COVID-19): A review. JAMA 2020;324(8):782793. doi:10.1001/jama.2020.12839
6. Spinner CD, Gottlieb RL, Criner GJ, et al. Effect of remdesivir vs standard care on clinical status at 11 days in patients with moderate COVID-19: A randomized clinical trial. JAMA 2020;324(11):1048-1057. doi:10.1001/jama.2020.16349

7. Beigel JH, Tomashek KM, Dodd LE, et al. Remdesivir for the treatment of Covid-19-final report. N Engl J Med 2020;383(19):1813-1826. doi:10.1056/NEJMoa2007764

8. World Health Organization. WHO recommends against the use of remdesivir in COVID-19 patients. https://www.who. $\mathrm{int} /$ news-room/feature-stories/detail/who-recommendsagainst-the-use-of-remdesivir-in-covid-19-patients. Accessed November 20, 2020.

9. Simonovich VA, Burgos Pratx LD, Scibona P, et al. A randomized trial of convalescent plasma in Covid-19 severe pneumonia [published online ahead of print, 2020 Nov 24]. N Engl J Med 2020;10.1056/NEJMoa2031304. doi:10.1056/ NEJMoa2031304

10. EyeWire. NIH panel finds "insufficient" data to support use of plasma for COVID-19 https://eyewire.news/articles/ nih-panel-finds-insufficient-data-to-support-use-of-plasmafor-covid-19/ Accessed November 20, 2020.

11. U.S. Food and Drug Administration. Coronavirus (COVID19) Update: FDA authorizes monoclonal antibody for treatment of COVID-19. https://www.fda.gov/news-events/ press-announcements/coronavirus-covid-19-update-fdaauthorizes-monoclonal-antibody-treatment-covid-19. Accessed November 20, 2020.

12. Chen $P$, Nirula A, Heller B, et al. SARS-CoV-2 neutralizing antibody LY-CoV555 in outpatients with Covid-19 [published online ahead of print, 2020 Oct 28]. N Engl J Med 2020; NEJMoa2029849. doi:10.1056/NEJMoa2029849

13. RECOVERY Collaborative Group, Horby P, Lim WS, et al. Dexamethasone in hospitalized patients with Covid-19-preliminary report [published online ahead of print, $2020 \mathrm{Jul}$ 17]. N Engl J Med 2020; NEJMoa2021436. doi:10.1056/ NEJMoa2021436

14. Lamontagne $\mathrm{F}$, Agoritsas $\mathrm{T}$, Macdonald $\mathrm{H}$, et al. A living WHO guideline on drugs for covid-19. BMJ 2020;370:m3379. Published 2020 Sep 4. doi:10.1136/bmj.m3379

15. Sultana J, Cutroneo PM, Crisafulli S, et al. Azithromycin in COVID-19 patients: pharmacological mechanism, clinical evidence and prescribing guidelines. Drug Saf 2020;43(8): 691-698. doi:10.1007/s40264-020-00976-7

16. The New York Times. F.D.A. grants emergency authorization of antibody treatment given to Trump. https://www.nytimes. com/2020/11/21/health/regeneron-covid-antibodies-trump. html Accessed November 20, 2020

17. Randolph HE, Barreiro LB. Herd immunity: understanding COVID-19. Immunity 2020;52(5):737-741. doi: 10.1016/j. immuni.2020.04.012 
18. Vignesh R, Shankar EM, Velu V, et al. Is herd immunity against SARS-CoV-2 a silver lining? Front Immunol 2020; 11:586781. Published 2020 Sep 30. doi:10.3389/fimmu.2020.586781

19. Center for Disease control and prevention. CDC COVID Data Tracker. https://covid.cdc.gov/covid-data-tracker/\#nationallab. Accessed Nov 15, 2020.

20. Aschwanden $\mathrm{C}$. The false promise of herd immunity for COVID-19. Nature 2020;587(7832):26-28. doi:10.1038/ d41586-020-02948-4

21. Wajnberg A, Amanat F, Firpo A, et al. Robust neutralizing antibodies to SARS-CoV-2 infection persist for months. Science 2020;370(6521):1227-1230. doi:10.1126/science. abd7728

22. lausen TM, Sandoval DR, Spliid CB, et al. SARS-CoV-2 Infection depends on cellular heparan sulfate and ACE2. Preprint bioRxiv. 2020;2020.07.14.201616. Published 2020 Jul 14. doi:10.1101/2020.07.14.201616

23. Trovato M, Sartorius R, D'Apice L, et al. Viral emerging diseases: challenges in developing vaccination strategies. Front Immunol 2020; 11:2130. Published 2020 Sep 3. doi:10.3389/ fimmu.2020.02130

24. Samrat SK, Tharappel AM, Li Z, et al. Prospect of SARS$\mathrm{CoV}-2$ spike protein: Potential role in vaccine and therapeutic development. Virus Res 2020;288:198141. doi: 10.1016/j. virusres.2020.198141

25. Polack FP, Thomas SJ, Kitchin N, et al. Safety and efficacy of the BNT162b2 mRNA Covid-19 vaccine [published online ahead of print, 2020 Dec 10]. N Engl J Med 2020;10.1056/ NEJMoa2034577. doi:10.1056/NEJMoa2034577

26. FolegattiPM,EwerKJ,AleyPK, etal. Safety and immunogenicity of the ChAdOx1 nCoV-19 vaccine against SARS-CoV-2: a preliminary report of a phase $1 / 2$, single-blind, randomised controlled trial [published correction appears in Lancet 2020 Aug 15;396(10249):466]. Lancet. 2020;396(10249): 467-478. doi:10.1016/S0140-6736(20)31604-4

27. Johnson and Johnson Prepares to Resume Phase 3 ENSEMBLE Trial of its Janssen COVID-19 Vaccine Candidate in the US; 2020. https://www.jnj.com/our-company/johnson- johnson-prepares-to-resume-phase-3-ensemble-trial-of-itsjanssen-covid-19-vaccine-candidate-in-the-us. Accessed Nov 22, 2020.

28. Moderna's COVID-19 vaccine candidate meets its primary efficacy endpoint in the first interim analysis of the phase 3 COVE Study; 2020. https://investors.modernatx.com/ news-releases/news-release-details/modernas-covid-19-vaccine-candidate-meets-its-primary-efficacy. Accessed Nov 22, 2020.

29. Abu-Rumeileh S, Abdelhak A, Foschi M, et al. GuillainBarré syndrome spectrum associated with COVID-19: an up-to-date systematic review of 73 cases [published online ahead of print, 2020 Aug 25]. J Neurol 2020;1-38. doi:10. 1007/s00415-020-10124-x

30. Akkad W, Salem B, Freeman JW, et al. Longitudinally extensive transverse myelitis following vaccination with nasal attenuated novel Influenza A(H1N1) Vaccine. Arch Neurol 2010;67(8):1018-1020. doi:10.1001/archneurol.2010.167

31. Dolgin E. Unlocking the potential of vaccines built on messenger RNA. Nature 2019;574(7778):S10-S12. doi:10.1038/ d41586-019-03072-8

32. Cafri G, Gartner JJ, Zaks T, et al. mRNA vaccine-induced neoantigen-specific $\mathrm{T}$ cell immunity in patients with gastrointestinal cancer. J Clin Invest 2020;130(11):5976-5988. doi:10.1172/JCI134915

33. Mubarak A, Alturaiki W, Hemida MG. Middle East Respiratory Syndrome Coronavirus (MERS-CoV): infection, immunological response, and vaccine development. J Immunol Res 2019; 2019:6491738. Published 2019 Apr 7. doi:10.1155/2019/6491738

34. Cann AJ. Replication of viruses. Encyclopedia of Virology 2008;406-412. doi:10.1016/B978-012374410-4.00486-6

35. Zaher HS, Green R. Fidelity at the molecular level: lessons from protein synthesis. Cell 2009;136(4):746-762. doi: 10.1016/j.cell.2009.01.036

36. World Health Organization. COVAX: Working for global equitable access to COVID-19 vaccines https://www.who. int/initiatives/act-accelerator/covax 